\section{Students mar anniversary}

\section{Munich}

Threats of violent protests at the West German University of Göttingen have forced officials to cancel ceremonies planned for 26 May to celebrate the university's 250th anniversary. A student "strike council" had vowed to blockade the doors to the university in protest against massive budget cuts proposed by the government of Lower Saxony.

A financial crisis has forced across-theboard cuts in Lower Saxony's budget. The Education Ministry has been asked to shoulder some of the burden by reducing expenditures by a proposed DM $130 \mathrm{mil}-$ lion over the next four years. The cuts are to be achieved by abolishing 371 tenured positions out of a total of 10,900 and reducing the budget for shorter-term positions by 3.5 per cent. Furthermore, students who study for more than a specified number of semesters are to pay fees of DM 500 per semester of further study. At present, students pay no fees, however long they study.

It seems to have been this measure that loosed the wave of protest in Göttingen. The university administration agreed in principle with the protesters said speaker Gerhard Gizler. University President Norbert Kamp wanted to go ahead with the ceremonies, but was ordered to cancel them by the government of Lower Saxony.

Lower Saxony speaker Joachim Werren justified the introduction of student fees as a way of reducing the number of people who "take advantage of their student status" to obtain reduced insurance rates and other benefits. This claim was rejected by the Westdeutschen Rektorenkonferenz (WRK), the organization of university heads. A spokesman for WRK explained that most students have to work to support themselves and it is for that reason that they stay in the university so long.

The proposal to cut back on personnel has encountered an equally critical response from the Public Servants' Union, which has denounced them as cuts by the "lawnmower method" rather than a response to programmed goals. But an acceptable compromise might be found, said Gizler, if the universities themselves are allowed to choose where the cuts are to be made. It might be wiser, he said, to offer extra support to a renowned university such as Göttingen - at the expense of other institutions - rather than reduce it to mediocrity.

Further student protests might be touched off if Lower Saxony's cabinet does not modify its original proposal. A decision is expected on 2 June.

Steven Dickman

\title{
Ambitious plans for CNR give hope to Italian scientists
}

Rome

ITALIAN research is to be fertilized by the injection of a billion lire ( $£ 500$ million) over the next five years. On 28 May, the Comitato Interministeriale per la Programmazione Economica (CIPE), the government body for economic planning, approved investment in ten projects devised by the Consiglio Nazionale delle Ricerche (CNR), the Italian research council.

In the ten CNR projects, apart from new discoveries in fundamental science, it is expected that there will be new products to market, especially in biotechnology and fine chemistry. Materials research is expected to yield advanced high-performance products, and telecommunications various experimental prototypes, while a supercomputer programme is designed to help integrate CNR projects with the European Esprit programme and to enable Italy to keep up with the latest trends in artificial intelligence. Other areas included in the plan are robotics, electro-optics, fine chemistry superconductors, cryogenics, building materials and town planning.

The projects will span the period $1987-$ 91. They will involve 1,250 research groups at CNR institutes, universities and

\section{Time Inc. runs out on Discover magazine}

\section{Washington}

DISCOVER, the last survivor of a boom in popular science magazines, has been sold, giving its publisher, the massive Time Inc., its first magazine failure in recent memory. Declining interest in science seems not to blame, for Discover's circulation is close to 900,000 . Rather, it seems that advertisers are not much interested in the kind of people that read science magazines. Discover could not continue at Time Inc. without a big rise in advertising revenues.

The new owner, Family Media Inc., publisher of such magazines as Health, Savvy and Homeowner, will pay \$26 million for Discover. The first issue under its control will appear in September, but both that and the following issue will rely on material already in preparation by Discover's staff. After that, the magazine may change, but Family Media Inc. has yet to announce an editorial policy or appoint an editor-in-chief.

The prospects for Discover at Time Inc. had seemed to improve last year after $\$ 5$ million was spent to buy up two competitors, Science 86 and Science Digest, and offer their readers subscription transfers. But even that boost proved insufficient - industrial laboratories and will occupy 23,400 man-years of effort.

Senator Luigi Granelli, the minister of research, says that state expenditure will be increased by a contribution of 48 per cent from industry, which means that a total of a million million lire will be devoted to research and development. One objective of the new plan is that there should be a public incentive in specific fields for a deeper involvement of private companies in advanced applied research. Granelli has been minister of research since 1983 , and the scientific community hopes he will be reconfirmed in that position after the elections on 14 June.

The approval by CIPE will enable CNR to make 600 grants to researchers in the fields now specified; there will be a further 500 contracts from collaborating industries, according to Professor Luigi Rossi Bernardi, the CNR president.

During the same CIPE session, the Italian government approved 76,000 million lire ( $\$ 50$ million) for the $1.5 \mathrm{GeV}$ synchrotron radiation source to be built at Trieste (see Nature 327, 5; 1987), while a first share of 209,000 million lire has been allocated for this year's start on the national research programme in biotechnology.

Paola De Paoli

within Time Inc.'s structure, at least. Time Inc. is known for the lavish scale of its operations. Discover, a monthly, had a staff of 74, including 37 on editorial. Discover's stablemates, Time, Life and Money (magazines), could afford to do things in style. Time's advertising revenue alone last year was $\$ 430$ million.

Discover could manage an advertising revenue of only $\$ 7$ million last year. Prodigious efforts had, according to Discover, generated a $\mathbf{5 0}$ per cent rise in the first half of this year, and brought in a handful of cigarette and liquour advertisements. But big advertisers continued to regard Discover readers as unlikely to buy their products. Home computer advertisers had mainly fled to the specialist computer hobby magazines.

Under Family Media Inc.'s ownership, revenue will be sought by offering advertisements in tandem with other magazines in the group. The editorial staff will be lean. Some of Discover's current staff will be kept on and a few, particularly those on the management side, remain at Time Inc. But most will be taking severance payments, described by staff as generous, and looking for work elsewhere.

Alun Anderson 